\title{
Role of tranexamic acid to reduce blood loss and transfusion of allogeneic blood in the field of surgery
}

\author{
Indra K. Shrestha ${ }^{1}$, Yong Yu Si ${ }^{2}$, Jian PingTao ${ }^{3}$ \\ ${ }^{1}$ Resident, ${ }^{2}$ Professor and Director, ${ }^{3}$ Professor and Vice Director, Department of Anesthesiology, Second Affiliated \\ Hospital of Kunming Medical University, Yunnan, Kunming, Dianmian Avenue 374, 650101, China
}

Tranexamic acid is widely used as an antifibrinolytic drug to reduce blood loss intraoperative and postoperative time periods as well as to reduce transfusion of allogeneic blood. After releasing in the market, multidisciplinary surgeries have wide use of tranexamic acid due to its antifibrinolytic effect to reduce bleeding and transfusion of blood. In literature, there were mentioned a few adverse effects like thromboembolism, seizure, anaphylactic reaction, etc which are still unsolved questions to date. The aim of this review to minimize the blood loss from acute bleeding in different situations by updating the doses used in a different clinical scenario, since the release of tranexamic acid. It also gives an idea about appropriate doses to reduce blood loss, need for blood transfusion, minimize adverse effects and to understand the wide scope of application of TXA to date.

Key words: Tranexamic acid; Blood loss; Transfusion; Surgery

\section{INTRODUCTION}

In present days clinical use of Tranexamic acid is widespread as an antifibrinolytic agent. Tranexamic acid is a synthetic antifibrinolytic amino acid derivative that inhibits the lysine binding sites of plasminogen and plasmin, thus result to reduce fibrinolysis. In major surgery, after an injury to tissues, releases the inflammatory mediators, tissue factor, and activates coagulation cascade which leads to hyperfibrinolysis that results in an increase in bleeding. Tranexamic acid is used in pediatric, adult and geriatric patients in various disciplines of surgeries such as Cardiac surgery, liver surgery, Gynecological \& Obstetrics Surgery, Spine Surgery, Orthopedic (Knee joint replacement and Hip fracture) surgery, Urological surgeries, ENT. Blood loss is a prominent problem,especially in major surgeries. Other antifibrinolytics like non-specific serine protease inhibitor aprotinin, the inhibitors of plasminogen activation epsilonamino-capronic acid (EACA) also used for treatment and prophylaxis of bleeding, but since 2007 aprotinin has withdrawn from the market due to massive side effects in cardiovascular surgery especially in open-heart surgery.
Since 1960 tranexamic acid was released. According to the literature, it was first prescribed to females with heavy menstrual bleeding and to patients with hereditary bleeding disorders. ${ }^{1}$ Since 2011, WHO- World Health Organization added TXA as an essential medicine list. ${ }^{2}$

\section{Complications of transfusion}

- Infections especially viral-like HIV, HBV, HCV

- Alloimmunization:

i). Alloimmunization against RBCs: It occurs as an acute intravascular hemolytic transfusion reaction. Hemolysis can occurs due to RBC alloantibodies.

ii). Alloimuniztion against Platelets: It occurs as refractoriness to platelet transfusion, where an increase in the platelet count after platelet transfusion that is significantly low value than expected. Post transfusion purpura may occur, which is associated with the presence of platelet alloantibodies.

iii). Alloimmunization against Granulocytes: It results in refractoriness to granulocyte transfusion, which occurs febrile nonhemolytic transfusion reactions. 
- Transfusion-related acute lung injury

- Transfusion-associated circulatory overload.

\section{Contraindications of TXA}

- Subarachnoid hemorrhage

- Hypersensitivity to tranexamic acid

- History of convulsion

- Upper renal tract bleeding-contraindicated due to the possibility of clot retention may lead to obstructing the urinary tract and colic.

- Acute venous and arterial thrombosis

- Pregnancy especially in early stage.

\section{Comparison}

\section{Aprotinin vs TXA}

Aprotinin has been withdrawn from the market since 2007 due to the high risk of renal failure, myocardial infarction, stroke, death in large observational studies. ${ }^{3}$ Mangano et al. reported that the use of aprotinin increased the risk of postoperative complications after cardiac surgery and an increased mortality rate. ${ }^{4}$ According to BART trial which was published in 2007, originally designed as a multicenter trial comparing whether aprotinin was superior to TXA and epsilon aminocaproic acid in decreasing the risk of massive postoperative bleeding in patients undergoing high-risk cardiac surgery and the trial was terminated early due to higher rate of death in patients receiving aprotinin. ${ }^{4,5}$ Thus, TXA became the choice of antifibrinolytic in cardiac and non-cardiac surgery. Remarkable is an especially neurologic complication in pediatric patients and in patients undergoing open-heart surgery. ${ }^{6,7}$

\section{Epsilon-aminocaproic acid (EACA) vs Tranexamic acid (TXA)}

Bradley et al. demonstrated through a randomized control trial for hip and knee arthroplasty procedures, EACA is associated with increased perioperative blood loss compared with TXA, however, there is no significant difference in the transfusion rate. ${ }^{8}$ Osman et al. reported through systematic review and meta-analysis that there is no significant difference in efficacy between TXA and EACA and their studies show that estimated blood loss was similar between the two groups [ $95 \%$ confidence interval $(\mathrm{CI})-0.50,0.04$; $\mathrm{Z}=1.69 ; \mathrm{P}=0.09]$. There were no differences between the two groups regarding the percentage of patients requiring transfusion $(95 \% \mathrm{CI} 0.14,4.13 ; \mathrm{Z}=0.31 ; \mathrm{P}=0.76)$. There was no difference in the pre- and post-operative hemoglobin differences between the two groups (95\% CI -0.36, 0.24; $\mathrm{Z}=0.38 ; \mathrm{P}=0.70)$. There was no difference in the average number of transfused units $(95 \% \mathrm{CI}-0.53,0.25 ; \mathrm{Z}=0.71$; $\mathrm{P}=0.48 .{ }^{9}$ In a prospective randomized trial, Kushagra et al. mentioned that tranexamic acid is more effective at reducing postoperative drainage and total blood losses compared with epsilon-aminocaproic acid. ${ }^{10}$

\section{Efficacy of TXA in cardiac surgery}

In major cardiac surgery tranexamic acid has been used in a large numbers of controlled trials with various dosing schemes in which the largest doses seem to be associated with neurotoxicity; due to this reason ISMICS (International Society for Minimally Invasive Cardiothoracic Surgery) recommended total dose of $100 \mathrm{mg} / \mathrm{kg}$ especially in patients over 50 years of age. ${ }^{1}$ Sigau et al. demonstrated that high dose of TXA $30 \mathrm{mg} / \mathrm{kg}$ bolus with $16 \mathrm{mg} / \mathrm{kg} / \mathrm{hr}$ with $2 \mathrm{mg} / \mathrm{kg}$ priming is more effective to reduce blood loss and transfusion as compared to low dose of $10 \mathrm{mg} / \mathrm{kg}$ bolus with $1 \mathrm{mg} / \mathrm{kg} / \mathrm{hr}$ with $1 \mathrm{mg} / \mathrm{kg}$ priming. ${ }^{11}$ Koster et al reported that in retrospective multivariate regression, the TXA use is associated with increased risk of postoperative seizure in patients having cardiac surgery with cardiopulmonary bypass $[\mathrm{OR}=1.703, \mathrm{P}=0.045]$ and increased in hospital mortality $[\mathrm{OR}=1.89, \mathrm{P}=0.005]$. In open-heart surgery, the use of TXA has an increased risk of seizure but no risk for coronary artery bypass graft. ${ }^{12}$ Hodgson et al. mentioned that in cardiac surgery patients having high risk of bleeding during surgery should get high dose of TXA@30mg/kg bolus + 16 mg/kg/hr +2 mg/kg priming while in patients with low risk of bleeding should get low dose of TXA@10 mg/kg bolus + 1 mg/kg/hr + $1 \mathrm{mg} / \mathrm{kg}$ priming with the consideration towards potential dose-related risk of seizure. ${ }^{13}$ Baric et al. administered a tranexamic acid of $2.5 \mathrm{gm}$ in the pericardial cavity in cardiac surgery before sternum closure, which demonstrates a significant reduction in postoperative bleedingcompared with placebo. ${ }^{14}$ In a prospective, randomized, doubleblind study, Reid et al. demonstrated that higher doses as $100 \mathrm{mg} / \mathrm{kg}$ bolus followed by $10 \mathrm{mg} / \mathrm{kg} / \mathrm{hr}$ maintenance showed a reduction in the total blood loss by $24 \%$ and total blood transfusion volume by $38 \%$ in children undergoing cardiac surgery. ${ }^{15}$

\section{Efficacy of TXA in spinal surgery}

On the basis of recently published literature, in spinal surgery, TXA is effective to reduce intraoperative, postoperative blood loss. Tranexamic acid also minimizes the rate of transfusion of blood products intraoperatively and postoperative time period. In systematic review and meta-analysis, Shanyi et al. mentioned that dose-dependent efficacy of TXA on allogeneic blood transfusion through subgroup analysis in his meta-analysis. ${ }^{16}$ He reported that high dose of TXA (10-100 mg/ kg bolus with maintenance dose greater than $10 \mathrm{mg} / \mathrm{kg} / \mathrm{hr}$ ) is more effective than low dose (no more than $10 \mathrm{mg} / \mathrm{kg}$ bolus with maintenance dose no more than $10 \mathrm{mg} / \mathrm{kg} / \mathrm{hr}$ ) to reduce blood loss and minimize allogeneic transfusion. ${ }^{16}$ In literature, most of the different spinal surgeries were used a various range of TXA doses as abolus and maintenance, like $5 \mathrm{mg} / \mathrm{kg}, 10 \mathrm{mg} / \mathrm{kg}$, $15 \mathrm{mg} / \mathrm{kg}$ and $20 \mathrm{mg} / \mathrm{kg}$ as a low bolus doses and $30 \mathrm{mg} / \mathrm{kg}$, $50 \mathrm{mg} / \mathrm{kg}$ and $100 \mathrm{mg} / \mathrm{kg}$ as a high bolus doses to reduce 
the blood loss, cell salvage and requirements of blood transfusion. The commonly used maintenance doses were $1 \mathrm{mg} / \mathrm{kg} / \mathrm{hr}, 5 \mathrm{mg} / \mathrm{kg} / \mathrm{hr}, 10 \mathrm{mg} / \mathrm{kg} / \mathrm{hr}$. In retrospective study 2015, Vinicius et al. mentioned that tranexamic acid is a low cost, effective and safe for reducing perioperative bleeding during operations to treat scoliosis with posterior instrumentation. ${ }^{17}$ In a randomized trial, David et al. reported that in pediatric who underwent posterior spinal fusion for scoliosis received $28 \%$ less blood when given prophylactic TXA $10 \mathrm{mg} / \mathrm{kg}$ bolus with $1 \mathrm{mg} / \mathrm{kg} / \mathrm{hr}$ maintenance as compared to the placebo group. ${ }^{18}$ In a retrospective study, Jingming et al. mentioned that in their study they evaluated blood loss, RBL, and transfusion requirements in the patient who underwent posterior vertebral column resection (PVCR) found the blood loss in the TXA group decreased by approximately $57.4 \% .{ }^{19}$ In a retrospective cohort study, Daniel J et al. compared effectiveness of high dose $(50 \mathrm{mg} / \mathrm{kg}$ bolus, $5 \mathrm{mg} / \mathrm{kg} / \mathrm{hr}$ maintenance) of TXA versus low dose of TXA $(10 \mathrm{mg} / \mathrm{kg}$ bolus, $1 \mathrm{mg} / \mathrm{kg} / \mathrm{hr}$ maintenance), found the high dose TXA group had significantly less intraoperative blood loss approximately $30 \%$ and a decreased RBC transfusion requirements by approximately $60 \%$, compared to low dose TXA group. ${ }^{20}$ In literature documented that TXA has effective and safe to reduce blood loss in the multi level thoracic spinal canal stenosis using trabeculectomy with posterior laminectomy and posterolateral bone graft fusion, where they reported reduction in need for blood transfusion, shorten the extubation time and the length of hospital stay with no risk of postoperative hemostatic dysfunction or postoperative DVT. ${ }^{21}$

\section{Efficacy in knee and hip arthroplasty}

In a prospective cohort study, Mannova et al. reported that the administration of tranexamic acid in two IV doses of $10-15 \mathrm{mg} / \mathrm{kg}$ to patients with total knee and hip arthroplasty has proven to be efficient to reduce blood loss. ${ }^{22,23}$ In retrospective study, Porter et al. demonstrated that administration of tranexamic acid to high-risk patient (risk factors such as DVT, PE, MI, CVA) of total knee arthroplasty and total hip arthroplasty is not associated with an increase in adverse outcomes where they studied adverse outcomes between 20 high-risk patients who received TXA and high-risk patients who did not receive TXA (OR 1.00, 21 CI 0.85 -1.18). There were also no differences when evaluating odds of 90 days post-operative DVT and PE (OR 0.84, 95\% CI: 0.59, 1.19) nor MI and CVA (OR: 0.91, 95\% CI: 0.56, 1.49) for 23 high-risk patients receiving TXA vs high-risk patients who did not receive TXA. ${ }^{24}$ In retrospective study, Huang et al. showed that the hemophiliacs treated with TXA had less perioperative blood loss, hidden blood loss, transfusion rate, a lower ratio of postoperative knee swelling, less postoperative joint pain, lower levels of inflammatory biomarkers and better joint function where they found usage of TXA can decrease not only the perioperative blood loss $(p=0.001)$, transfusion rate $(p=0.017)$ and supplemental amount of FVIII ( $p<0.001$ ) but also swelling ratio, surgical joint pain. ${ }^{23}$

Therefore reducing cost as well as hospital stay. ${ }^{25,26}$ Despite the higher risk of blood loss and need for transfusion following revision total knee arthroplasty, lowest effective dose and least costly regimen should be used due to similar effect in the management of blood loss with all TXA dosing regimens. ${ }^{27}$

\section{Efficacy of TXA in gynecology and obstetrics}

i). C-Section: Bouthors et al. reported that the tranexamic acid reduces the intraoperative bleeding as well as minimize postpartum volume, duration of surgery, and transfusion need but not the hysterectomy rate. ${ }^{28}$

ii). Myomectomy: First time in literature, in a prospective randomized double-blind placebo control study, Caglar et al. demonstrated that the use of tranexamic acid shows the significant effect to reduce preoperative and postoperative bleeding and blood transfusion, a patient undergoing myomectomy and have no adverse effects in a tranexamic group as well as in control group. ${ }^{29} \mathrm{In}$ a randomized control trial, Shaaban et al. mentioned that tranexamic acid reduces blood loss during and after myomectomy for a patient with multiple uterine fibroids. ${ }^{30}$

iii). Antepartum and Postpartum Hemorrhage: Early detection and management of both antepartum and postpartum hemorrhage decrease the rate of mortality. In the management of placenta abruption, TXA plays a vital role to reduce perinatal mortality if routinely use as an immediate treatment. ${ }^{31}$ Postpartum hemorrhage is the most common cause of maternal mortality in developing as well as a developed country. Shakur et al. reported that the use of immediate tranexamic acid as soon as bleeding starts reduces death due to bleeding in women with post-partum hemorrhage with no adverse effect and his study included thetranexamic acid $(\mathrm{n}=10051)$ or placebo $(\mathrm{n}=10009)$, of whom 10036 and 9985, respectively, were included in the analysis where death due to bleeding was significantly reduced in women given tranexamic acid (155 [1 5\%] of 10036 patients vs 191 [1.\%\%] of 9985 in the placebo group, risk ratio [RR] $0.81,95 \%$ CI $0.65-1.00 ; p=0.045$ ), especially in women given treatment within 3 hours of giving birth (89 [1.2\%] in the tranexamic acid group vs 127 [1.7\%] in the placebo group, RR 0.69 , 95\% CI $0.52-0.91$; $\mathrm{p}=0 \cdot 008) .{ }^{32-34}$ In a case report, Schröder et al. reported that the isolated hyperfibrinolysis is a potential cause of bleeding during conservative management of placenta increta and percreta, where the use of tranexamic acid is effective to treat bleeding. ${ }^{35}$ 


\section{Efficacy of TXA in urological surgery}

In urological surgeries blood loss also a prominent problem that may lead to increase risk of morbidity and mortality of patients. Bansal et al. demonstrated that the use of $0.1 \%$ tranexamic acid in irrigant fluid was efficient which significantly reduces perioperative blood loss and requirement of blood transfusion during percutaneous nephrolithotomy (PCNL). ${ }^{36}$ In systematic review and meta-analysis, Sergio et al. showed that in prostate surgery, tranexamic acid is effective to reduce perioperative blood loss but has no significant effect for neither need for transfusion of blood nor help to increase $\mathrm{Hb}$ value at the end of the surgery. ${ }^{37}$ Prokopchuk et al. reported a case 57 year old male patient of lifethreatening hemorrhage in prostate cancer associated with disseminated intravascular coagulation (DIC) with excessive fibrinolysis in which they treated with tranexamic acid and suggested that use of an antifibrinolytic agent be considered in the setting of transfusion-resistant bleeding when clinical and laboratory evidence supports the presence of excessive fibrinolysis. ${ }^{38}$ Zaid et al. demonstrated that the tranexamic acid with $10 \mathrm{mg} / \mathrm{kg}$ bolus and $2 \mathrm{mg} / \mathrm{kg} / \mathrm{hr}$ of maintenance dose significantly reduction in perioperative blood transfusion in patients undergoing open radical cystectomy and has no increased risk of venous thromboembolism (VTE). ${ }^{39,40}$ The major problem during radical prostatectomy and in TURP leads to significant bleeding and increases morbidity and mortality of patients. Longo et al. showed that in radical prostatectomy and in TURP, TXA has been used to reduce intraoperative blood loss and the need for transfusion, without increasing the risk of DVT and PE in prostate cancer and BPH. ${ }^{41}$

\section{Efficacy of TXA in liver surgery}

Liver resection is the common practice treatment for patients with primaryor metastatic malignancies of liver, benign liver tumors, and other biliary diseases bleeding is the prominent problem. The mechanism of bleeding in liver resection may differ from other surgeries. In liver resection may alter the systematic hemostatic function, possibly by activation of hyperfibrinolysis. In Literature as mentioned, the two most commonly used doses of TXA are $1 \mathrm{~g}$ bolus followed by $1 \mathrm{~g}$ over $8 \mathrm{~h}$ (from the CRASH-2 trial) and $1 \mathrm{~g}$ bolus followed by $10 \mathrm{mg} / \mathrm{kg} / \mathrm{hr}$ in liver transplantation. ${ }^{42}$ In a randomized trial, Badenoch et al. demonstrated that the efficacy of TXA in reducing blood loss and transfusion requirements during liver transplantation without increasing the risk of thromboembolic events. ${ }^{43}$ In literature, RCTs demonstrated approximately (30-40)\% reduction in bleeding and need for transfusion requirements during orthotopic liver transplantation as compared to placebo group. ${ }^{43}$ Karanicolas et al. demonstrated no evidence of hyperfibrinolysis during liver resection by thromboelastography (TEG), found no alteration in hemostatic function by TXA. ${ }^{44}$ In a randomized control trial, Wu et al. demonstrated that perioperative parenteral TXA in patient undergoing liver resection had no blood transfusion needed as compared to no parenteral TXA (16\% blood transfusion) patient. ${ }^{45}$

\section{Efficacy of TXA in ENT \\ Epistaxis}

Epistaxis is a prominent bleeding condition, among the total percentage of epistaxis, nearly about $60 \%$ of the population may need medical intervention whereas many cases were severely bleed, inevitable admission in hospital for further clinical intervention or even death, if not early management. Common clinical practices for management of epistaxis are an application of topical vasoconstrictor, chemical cautery with silver nitrate, if failed above methods then anterior nasal packing is applied which has effective but discomfort to the patient as well as patient experience pain and sensation of nasal obstruction. Extensive evidence supporting the use of both intravenous TXA (CRASH 2) and topical TXA (Cochrane review) in over 30,000 patients supports an excellent safety profile, with no reported complications in patients receiving topical TXA. ${ }^{46-49}$ In RCTs Reuben et al. reported that tranexamic acid is effective to reduce nasal packing for the management of epistaxis. ${ }^{50-52}$ Tranexamic acid is cheap and convenient as compared to nasal packing and even easy to apply via intravenous or topical forms as per need in emergency situations.

\section{An adverse effect of TXA}

Most commonly seen adverse effects of tranexamic acid in clinical practices is gastrointestinal disturbances (nausea, vomiting, and diarrhea), drop of blood pressure/ dizziness followed by rapid intravenous administration, incidental allergic skin reactions, infrequent temporal vision impairment, seizure, thromboembolism. Jeniffer et al. reported that with a dose of $5 \mathrm{mg} / \mathrm{kg}$ bolus with an infusion of $5 \mathrm{mg} / \mathrm{kg} / \mathrm{hr}$ which causes an anaphylactic reaction in a 15 years adult patient with a weight of $50.8 \mathrm{~kg}$ undergoing posterior spinal fusion in scoliosis surgery. The first case of anaphylactic reaction to TXA reported a 72 -year-old man who underwent CABG surgery. ${ }^{53}$

In a retrospective study, Michael et al. reported that $7.9 \%$ of patients have an incidence of convulsive seizures, especially in open heart surgery. ${ }^{3}$ Murkin et al.mentioned that the administration of high dose tranexamic acid 1.3\%$3.8 \%$ of patients has an incidence of clinical convulsive seizure, especially in older patients in conjunction with cardiopulmonary bypass and open-chamber cardiac surgery. 


\section{DISCUSSION}

In clinical practices, tranexamic acid used commonly in management of postpartum hemorrhage, menorrhagia, and metrorrhagia, gastrointestinal bleeding, bleeding in urinary tract infections, postoperative bleeding followed by prostate or urinary tract surgery, and also as an antidote in bleeding which needs emergency treatment who are in fibrinolytic treatment. The safety measures were evaluated by investigating myocardial biomarkers especially CK-MB, creatinine and diagnosis of myocardial infarction, ischemic stroke, intracerebral hemorrhage, convulsive seizures, acute renal failure. Xie et al. declared that a loading dose of $100 \mathrm{mg} / \mathrm{kg}$ with a maintenance dose of $10 \mathrm{mg} / \mathrm{kg} / \mathrm{hr}$ showed no signs of renal toxicity, seizures, DVT, or MI upon assessment. ${ }^{19}$ Efficacy can be measured by evaluating the parameters like the need for transfusion of blood products and total intraoperative and postoperative (first 6 hours, 24 hours and 48 hours of surgery) blood loss. In a randomized prospective, double-blind, multicenter study, Wong et al. mentioned that the efficacy for reducing perioperative blood loss and blood transfusions in adult patients with selective thoracolumbar posterior fusion. ${ }^{54}$ In various literature mentioned that $100 \mathrm{mg} / \mathrm{kg}$ bolus intravenous was a maximum safe dose of TXA infused over 1530 minutes followed by a maintenance dose of $10 \mathrm{mg} / \mathrm{kg} /$ $\mathrm{hr}$ and literature has shown that early administration of tranexamic acid in severe trauma can significantly decrease the rate of mortality.

\section{CONCLUSION}

In this review concluded that tranexamic acid is an essential drug of choice for multi-disciplinary surgeries and the management of acute bleeding in trauma patients as early as possible which minimizes the need for transfusion, decreases the risk of mortality, decreases hospital stay and minimizes cost burden. Common effective routes are intravenous and topical for acute management of bleeding with no adverse effect. In literature, there still lacking optimal doses to be applied in respective surgeries as mentioned in this review for generalization either in pediatric or in adult patients.

\section{REFERENCES}

1. Tengborn L, Blomback M and Berntorp E. Tranexamic acid- an old drug still going strong and making a revival. Thrombosis Research 2015;135:231-242.

2. Pabinger I, Fries $D$, Schöchl $H$, Streif $W$ and Toller $W$. Tranexamic acid for treatment and prophylaxis of bleeding and hyperfibrinolysis consensus report. Wien Klin Wochenschr 2017; 129:303-316.
3. Sander M, Spies CD, Martiny V, Rosenthal C, Wernecke KD and von Heymann C. Mortality associated with administration of high dose tranexamic acid and aprotinin in primary openheart procedures: a retrospective analysis. Critical Care 2010, 14:R148.

4. Mangano D, Tudor IC, Dietzel C, Group MSoPIR and Foundation IRaE. The risk associated with aprotinin in cardiac surgery. N Engl J Med 2006;354:353-365.

5. Fergusson DA, Hébert PC, Mazer CD, Fremes S, MacAdams C, Murkin JM, et al. A comparison of aprotinin and lysine analogues in high risk cardiac surgery. N Engl J Med 2008;358:2319-2331.

6. Murkin JM, Falter F, Granton J, Young B, Burt C and D Chu M. High-dose tranexamic acid is associated with nonischemic clinical seizures in cardiac surgical patients. Anesth Analg 2010;110(2):350-353.

7. Breuer T, Martin K, Wilhelm M, Wiesner G, Schreiber C, Hess J, et al. The blood sparing effect and the safety of aprotinin compared to tranexamic acid in pediatric cardiac surgery. Eur $\mathrm{J}$ Cardiothorac Surg 2009, 35:167-171.

8. Bradley KE, Ryan SP, Penrose CT, Grant SA, Wellman SS, Attarian DE, et al. Tranexamic acid or epsilon-aminocaproic acid in total joint arthroplasty- A randomized controlled trial. Bone Joint J 2019;101-B(9):1093-1099.

9. Riaz O, Aqil A, Asmar S, Vanker R, Hahnel J, Brew C, et al. Epsilon-aminocaproic acid versus tranexamic acid in total knee arthroplasty: a meta-analysis study. J Orthop Traumatol 2019;20(1):28.

10. Verma K, Errico T, Diefenbach C, Hoelscher C, Peters A, Dryer J, et al. The Relative Efficacy of Antifibrinolytics in Adolescent Idiopathic Scoliosis: A Prospective Randomized Trial. The Journal of Bone and Joint Surgery 2014; 96(10):e80.

11. Sigaut S, Tremey B, Ouattara A, Couturier R, Taberlet C and Grassin-Delyle S. Comparison of two doses of tranexamic acid in adults undergoing cardiac surgery with cardiopulmonary bypass. Anesthesiology 2014;120:590-600.

12. Koster A, Börgermann J, Zittermann A,Lueth JU, GillisJanuszewski T and Schirmer U. Moderate dosage of tranexamic acid during cardiac surgery with cardiopulmonary bypass and convulsive seizures: incidence and clinical outcome. $\mathrm{Br} \mathrm{J}$ Anaesth 2013;110:34-40.

13. Hodgson S, Larvin JT and Dearman C. What dose of tranexamic acid is most effective and safe for adult patients undergoing cardiac surgery? Interact Cardiovasc Thorac Surg 2015;21:384388.

14. Baric D, Biocina B and Unic D. Topical use of antifibrinolytic agents reduces postoperative bleeding: a double-blind, prospective, randomized study. Eur J Cardiothorac Surg 2007; 31:366-371.

15. Reid RW, Zimmerman AA, Laussen PC, Mayer JE, Gorlin JB and Burrows FA. The efficacy of tranexamic acid versus placebo in decreasing blood loss in pediatric patients undergoing repeat cardiac surgery. Anesth Analg 1997;84:990-996.

16. Shangyi Hui, Derong Xu, Zhinan Ren, Xin Chen, Liu Sheng, Qianyu Zhuang, et al. Can tranexamic acid conserve blood and save operative time in spinal surgeries? A Meta-analysis. The spinal Journal 2017.11.017.RJ.Ref: SPINEE 57550. In press 2017.11.22.

17. da Rocha VM, de Barros AG, Naves CD, Gomes NL, Lobo JC, Villela Schettino LC, et al. Use of tranexamic acid for controlling bleeding in thoracolumbar scoliosis surgery with posterior instrumentation. Rev Bras Ortop 2015;50(2):226-231.

18. Neilipovitz DT, Murto K, Hall L, Barrowman NJ and Splinter WM. A randomized trial of tranexamic acid to reduce blood transfusion for scoliosis surgery. Anesth Analg 2001; 93(1):82-87.

19. Xie J, Lenke LG, Li T, Yong Y S, Zhi Z, Yingsong W, et al. 
Preliminary investigation of high-dose tranexamic acid for controlling intraoperative blood loss in patients undergoing spine correction surgery. Spine J 2015; 15(4):647-654.

20. Johnson DJ, Johnson CC and Goobie SM. High-dose vs Lowdose Tranexamic Acid to Reduce Transfusion Requirements in Pediatric Scoliosis Surgery. J Pediatr Orthop 2017; 37:e552-e557.

21. Xue P, Yang J, Xu X, Liu T, Huang Y, Qiao F, et al. The efficacy and safety of tranexamic acid in reducing perioperative blood loss in patients with multilevel thoracic spinal stenosis. A retrospective observational study. Medicine (Baltimore) 2018;97(50):e13643.

22. Mannova J, Kubat P, Pospichal $M$ and Longin P. Evaluation of Efficacy of Systemic Administration of Tranexamic Acid (Exacyl) in Total Hip and Knee Arthroplasty - Prospective Cohort Study. Acta Chir Orthop Traumatol Cech 2019;86(2):118-123.

23. Hiippala ST, Strid LJ, Wennerstrand MI, Arvela JVV, Niemela HM, Mantyla SK, et al. Tranexamic Acid Radically Decreases Blood Loss and Transfusions Associated with Total Knee Arthroplasty. Anesthesia \& Analgesia 1997;84(4):839-844.

24. Porter SB, White LJ, Osagiede O, Robards CB and Spaulding AC. Tranexamic acid administration is not associated with an increase in complications in high-risk patients undergoing primary total knee or total hip arthroplasty: A retrospective casecontrol study of 38,220 patients. The Journal of Arthroplasty. In press 2019.

25. Huang ZY, Huang Q, Zeng HJ, Ma J, Shen B, Zhou ZK, et al. Tranexamic acid may benefit patients undergoing total hip/ knee arthroplasty because of hemophilia. BMC Musculoskeletal Disorders 2019;20:402.

26. Kyriakopoulos G, Oikonomou L, Panagopoulos A, Kotsarinis G, Vlachou M, Anastopoulos G, et al. Transfusion rate, hospital stay and cost-effectiveness of intravenous or local administration of tranexamic acid in total hip and knee arthroplasty. Orthopedic Reviews 2019;11(2):7866.

27. Fillingham YA, Darrith B, Calkins TE, Abdel MP, Malkani AL and Schwarzkopf R. Mark Coventry Award: A multicentre randomized clinical trial of tranexamic acid in revision total knee arthroplasty. The Bone \& Joint Journal 2019; 101-B(7_Supple_C),10-16.

28. Bouthors AS, Hennart B, Jeanpierre E, Baptiste AS, Saidi I, Simon E, et al. Therapeutic and pharmaco-biological, doseranging multicentre trial to determine the optimal dose of Tranexamic acid to reduce blood loss in hemorrhagic Cesarean delivery (TRACES): study protocol for a randomized, doubleblind, placebo-controlled trial. Trials 2018;19(1):148.

29. Caglar GS, Tasci $Y$ and Kayikcioglu F. Intravenous tranexamic acid use in myomectomy: a prospective randomized doubleblind placebo controlled study. Eur J Obstet Gynecol Reprod Biol 2008;137:227-231.

30. Shaaban MM, Ahmed MR, Farhan RE and Dardeer HH. Efficacy of Tranexamic Acid on Myomectomy-Associated Blood Loss in Patients With Multiple Myomas. Reproductive Sciences 2015;23(7):908-912.

31. Svanberg L, Astedt B and Nilsson IM. Abruptio PlacentaeTreatment with the Fibrinolytic Inhibitor Tranexamic Acid. Acta Obstetricia et Gynecologica Scandinavica 1980;59(2):127-130.

32. Shakur H, Roberts I, Fawole B, Chaudhri R, El-Sheikh M, Akintan A, et al. Effect of early tranexamic acid administration on mortality, hysterectomy, and other morbidities in women with post-partum hemorrhage (WOMAN): an international, randomized, double-blind, placebo-controlled trial. The Lancet 2017;389(10084):2105-2116.

33. Sebghati $M$ and Chandraharan E. An update on the risk factors for and management of obstetric hemorrhage. Women's Health 2017; 13(2):34-40.

34. Sudhof LS, Shainker SA and Einerson BD. Tranexamic Acid in the Routine Treatment of Post-Partum Hemorrhage in the United States: A Cost-Effectiveness Analysis. American Journal of Obstetrics and Gynecology 2019;221:275.e1-e12.

35. Schröder L, Pötzsch B, Rühl H, Gembruch U and Merz WM. Tranexamic Acid for Hyperfibrinolytic Hemorrhage During Conservative Management of Placenta percreta. Obstetrics \& Gynecology 2015;126(5):1012-1015.

36. Bansal A and Arora A. A double-blind, placebo-controlled randomized clinical trial to evaluate the efficacy of tranexamic acid in irrigant solution on blood loss during percutaneous nephrolithotomy: a pilot study from tertiary care center of North India. World Journal of Urology 2016;35(8):1233-1240.

37. Mina SH and Garcia-Perdomo HA. Effectiveness of tranexamic acid for decreasing bleeding in prostate surgery: a systematic review and meta-analysis. Central European Journal of Urology 2018;71:72-77.

38. Prokopchuk-Gauk $\mathrm{O}$ and Brose K. Tranexamic Acid to Treat Life-threatening Hemorrhage in Prostate Cancer-Associated Disseminated Intravascular Coagulation with Excessive Fibrinolysis. Cureus 2015;7(12):e428.

39. Zaid HB, Yang DY, Tollefson MK, Frank I, Winters JL, Thapa P, et al. Efficacy and Safety of Intraoperative Tranexamic Acid Infusion for Reducing Blood Transfusion During Open Radical Cystectomy. Urology 2016;92:57-62.

40. Breau RH, Lavallée LT, Cnossen S, Witiuk K, Cagiannos I, Momoli $F$, et al. Tranexamic Acid versus Placebo to Prevent Blood Transfusion during Radical Cystectomy for Bladder Cancer (TACT): Study Protocol for a Randomized Controlled Trial. Trials 2018;19:261.

41. Longo MA, Cavalheiro BT and de Oliveira Filho GR. Systematic review and meta-analyses of tranexamic acid use for bleeding reduction in prostate surgery. Journal of Clinical Anesthesia 2018;48:32-38.

42. Dalmau A, Sabaté A, Koo M, Bartolomé C, Rafecas A and Figueras J. The prophylactic use of tranexamic acid and aprotinin in orthotopic liver transplantation: a comparative study. Liver Transpl 2004;10:279-284.

43. Badenoch A, Sharma A, Gower S, Selzner M, Srinivas C, Wasowicz M, et al. The Effectiveness and Safety of Tranexamic Acid in Orthotopic Liver Transplantation Clinical Practice. Transplantation 2017;101(7):1658-1665.

44. Karanicolas PJ, Lin Y, Tarshis J, Law CHL, Coburn NG, Hallet J, et al. Major liver resection, systemic fibrinolytic activity, and the impact of tranexamic acid. HPB, 2016; 18(12):991-999.

45. Wu CC, Ho WM, Cheng SB, Yeh DC, Wen MC, Liu TJ, et al. Perioperative Parenteral Tranexamic Acid in Liver Tumor Resection. Annals of Surgery 2006; 243(2):173-180.

46. Roberts I, Shakur $\mathrm{H}$ and Afolabi A. The importance of early treatment with tranexamic acid in bleeding trauma patients: an exploratory analysis of the CRASH-2 randomized controlled trial. Lancet 2011;377:1096-1101.

47. Shakur H, Roberts I and CRASH-2 collaborators. Effects of tranexamic acid on death, vascular occlusive events, and blood transfusion in trauma patients with significant hemorrhage (CRASH-2): a randomized, placebo-controlled trial. Lancet 2010; 376(9734):23-32.

48. Ker K, Beecher D and Roberts I. Topical application of tranexamic acid for the reduction of bleeding. Cochrane Database Syst Rev 2013:CD010562.

49. Logan JK and Pantle H. Role of topical tranexamic acid in the management of idiopathic anterior epistaxis in adult patients in the emergency department. American Journal of Health-System Pharmacy 2016;73(21):1755-1759.

50. Reuben A, Appelboam A, Barton A, Vickery PJ, Body R, Hilton $M$, et al. Novel use of tranexamic acid to reduce the need 
for Nasal Packing in Epistaxis (NoPac) randomized controlled trial: research protocol. BMJ Open 2019; 9(2):e026882.

51. Kamhieh $\mathrm{Y}$ and Fox H. Tranexamic acid in epistaxis: a systematic review. Clinical Otolaryngology 2016;41(6):771-776.

52. Gottlieb M, Koyfman A and Long B. Tranexamic Acid for the Treatment of Epistaxis. Academic Emergency Medicine. The Society for Academic Emergency Medicine 2019; 00:1-2, ISSN 1553-2712.
53. Chiem J, Ivanova I, Parker A, Krengel W and Jimenez N. Anaphylactic reaction to tranexamic acid in an adolescent undergoing posterior spinal fusion. Pediatric Anesthesia 2017; ISSN 1155-5645.

54. Wong J, El Beheiry, Rampersaud YR, Lewis S, Ahn H, De Silva Y, et al. Tranexamic Acid Reduces Perioperative Blood Loss in Adult Patients Having Spinal Fusion Surgery. Anesthesia \& Analgesia 2008;107(5):1479-1486.

\section{Authors Contribution:}

IKS-Study design, manuscript preparation, literature search, reviewed the literature, critical revision of the manuscript; YYS-Concept of the study; JPT-Critical revision of manuscript and review of the study.

Work attributed to: Second Affiliated Hospital of Kunming Medical University, Yunnan, Kunming, Dianmian Avenue 374, 650101, China.

Orcid ID:

Dr. Indra Kumar Shrestha - (D) https://orcid.org/0000-0003-2379-2496

Prof. Yong Yu Si - (i) https://orcid.org/0000-0002-3058-4284

Prof. Jian Ping Tao - (1) https://orcid.org/0000-0001-5511-6834

Source of Support: National Natural Science Foundation of China (\#81060033), Conflict of Interest: None. 